\title{
Downregulation of miR-186 promotes the proliferation and drug resistance of glioblastoma cells by targeting Twist1
}

\author{
YIFENG XIONG $^{1}$, RENSHENG CHEN $^{1}$, LIZHEN WANG ${ }^{1}$, \\ SHANSHAN WANG ${ }^{1}$, YI TU ${ }^{1}$, LEI ZHU ${ }^{1}$ and CHUNLIANG WANG ${ }^{2}$ \\ Departments of ${ }^{1}$ Pathology and ${ }^{2}$ Neurosurgery, The First Affiliated Hospital of Nanchang University, \\ Nanchang, Jiangxi 330006, P.R. China
}

Received August 12, 2018; Accepted March 15, 2019

DOI: $10.3892 / \mathrm{mmr} .2019 .10207$

\begin{abstract}
Temozolomide (TMZ) is widely used as a chemotherapeutic agent in the treatment of glioma; however, the development of drug resistance remains a major obstacle in the effective treatment of glioblastoma. Increasing evidence has indicated that microRNAs (miRs) are involved in the drug resistance of glioma; however, the role of miR-186-5p in the TMZ resistance of glioblastoma remains unknown. In the present study, the role of miR-186-5p in the resistance of glioblastoma to $\mathrm{TMZ}$ was investigated. mRNA and protein expression levels were detected via reverse transcription-quantitative PCR and western blot analysis, respectively. It was determined that miR-186-5p was significantly downregulated in glioblastoma tissues and cell lines. Additionally, the expression of miR-186-5p was decreased, whereas that of Twist1 was upregulated during the development of drug resistance in glioma cells. The introduction of miR-186 into glioblastoma cells via transfection decreased the proliferation and TMZ resistance of glioblastoma cells, as determined via 5-ethynyl-2'-deoxyuridine and Cell Counting Kit-8 assays, whereas the inhibition of miR-186-5p induced opposing effects. Furthermore, luciferase reporter and expression rescue assays revealed that miR-186-5p bound to the 3'-untranslated region of Twist-related protein 1 (Twist1). In conclusion, the present study demonstrated that downregulation of miR-186-5p may contribute to the proliferation and drug resistance of glioblastoma cells via the regulation of Twistl expression. These results suggested that miR-186-5p may be a novel therapeutic target in the treatment of glioblastoma.
\end{abstract}

Correspondence to: Professor Chunliang Wang, Department of Neurosurgery, The First Affiliated Hospital of Nanchang University, 17 Yongwaizheng Street, Nanchang, Jiangxi 330006, P.R. China E-mail: wangchunliang2018@126.com

Key words: microRNAs, microRNA-186, Twist, temozolomide, glioblastoma, glioma

\section{Introduction}

Glioblastoma multiforme (GBM) is one of the most common malignant primary brain tumours in adults (1). Technological advances in surgery, radiotherapy and chemotherapy have been made in previous decades; however, the average overall survival time of patients with GBM is 14.6 months (2). As a result of the invasive growth of tumour cells, challenges include complete resection and low sensitivity to standard therapy $(3,4)$. Temozolomide (TMZ) is the standard first-line chemotherapeutic treatment for glioma; however, the overall clinical prognosis remains unsatisfactory due to the resistance of glioma cells to TMZ (5). Therefore, determination of the mechanisms underlying drug resistance is important for improving chemotherapeutic efficacy in GBM.

MicroRNAs (miRNAs/miRs) are a class of small noncoding RNAs, 20-22 nucleotides in length, which negatively regulate their target genes by binding to the 3'-untranslated region (3'UTR) of mRNA (6). miRNAs possess important roles in tumourigenesis, such as in the invasion and drug resistance of tumour cells $(7,8)$. miR-186 has been reported to affect the proliferation, infiltration, metastasis and drug resistance of various types of cancer, including ovarian, prostate and lung cancer (9-11). Downregulation of miR-186 results in the increased invasion and proliferation of non-small cell lung cancer (NSCLC) cells, and is associated with poor patient prognosis (11). Decreased miR-186 expression has also been detected in cisplatin-resistant ovarian cancer tissues and cell lines, and may act as a potent epithelial-mesenchymal transition (EMT) regulator that is involved in the drug resistance of ovarian cancer cells (9). however, the role of miR-186 in the chemoresistance of glioma cells remains unknown.

The highly conserved basic helix-loop-helix transcription factor Twist-related protein 1 (Twist1) has been proposed to act as an oncogenic transcription factor; increased expression of Twist proteins promotes tumour initiation, progression, metastasis, EMT, and protection from chemotherapy-induced apoptosis and senescence (12-15). Evidence has also suggested that Twist1 is upregulated in malignant glioma and promotes glioma cell invasion via the induction of mesenchymal molecular and cellular alterations (15). However, the role of Twist1 in the drug resistance of human glioma cells to $\mathrm{TMZ}$ is unclear. 
In the present study, it was reported that the expression levels of miR-186-5p were decreased, whereas Twist1 expression was upregulated during the development of drug resistance in glioma cells. Furthermore, it was revealed that decreased expression of miR-186-5p contributed to the proliferation and drug resistance of glioma cells via the direct targeting of Twist1. The results provided novel insight into the role of miR-186-5p and its downstream target, Twist1, in the drug resistance of glioma.

\section{Materials and methods}

Cell lines and tissue samples. Human U87 (U87 MG HTB-14, likely glioblastoma of unknown origin) and T98G glioblastoma cell lines were purchased from the American Type Culture Collection (ATCC). The human normal glial cell line HEB (ATCC0459) and 293T cells were purchased from Shanghai Beinuo Biotechnology Co., Ltd. Cells were cultured in DMEM (Gibco; Thermo Fisher Scientific, Inc.) supplemented with 10\% foetal bovine serum (Gibco; Thermo Fisher Scientific, Inc.), $100 \mathrm{mg} / \mathrm{ml}$ streptomycin and $100 \mathrm{IU} / \mathrm{ml}$ penicillin (Thermo Fisher Scientific, Inc.). Cells were maintained at $37^{\circ} \mathrm{C}$ in a $5 \% \mathrm{CO}_{2}$ humidified atmosphere. Human GBM ( $\left.\mathrm{n}=11\right)$ and normal brain specimens $(n=20)$ used in the present study were obtained from patients operated for glioma and epilepsy, respectively. The samples were collected from the Department of Neurosurgery, The First Affiliated Hospital of Nanchang University between January 2011 and December 2017. Patients with primary tumours that had not received radiotherapy or chemotherapy prior to surgery were included in the study. Detailed clinical data and surgical records were available. The age and sex distributions of patients are presented in Table I. Diagnosis of GBM was confirmed by histopathological examination. This study was approved by the Ethics Committee of The First Affiliated Hospital of Nanchang University and protocols were conducted according to the principles of the Declaration of Helsinki. Written informed consent was obtained from all patients in the study.

Reverse transcription-quantitative PCR (RT-qPCR). Cells were treated with $\operatorname{TMZ}(0,50,100$ and $200 \mu \mathrm{M}$; Sigma-Aldrich; Merck KGaA) for $24 \mathrm{~h}$ at $37^{\circ} \mathrm{C}$. Twist 1 expression was determined via RT-qPCR analysis. Total RNA was extracted from cell lines and tissues using TRIzol ${ }^{\circledR}$ reagent (Invitrogen; Thermo Fisher Scientific, Inc.). cDNA was synthesised from total RNA using the PrimeScript ${ }^{\circledR}$ RT reagent kit (Takara Biotechnology Co., Ltd.), according to the manufacturer's protocol. PCR reactions were performed using the $\mathrm{SYBR}^{\circledR}$ Premix Dimer Eraser kit (Takara Biotechnology Co., Ltd.) with the ABI Prism 7500 system (Applied Biosystems; Thermo Fisher Scientific, Inc.), under the following conditions: $4 \mathrm{~min}$ at $94^{\circ} \mathrm{C}$, then 40 cycles of $94^{\circ} \mathrm{C}$ for $30 \mathrm{sec}, 60^{\circ} \mathrm{C}$ for $30 \mathrm{sec}$ and $72^{\circ} \mathrm{C}$ for $60 \mathrm{sec}$. The expression of Twist1 was normalized to the expression of $\beta$-actin. For analysis of the expression of miR-186-5p, the TaqMan MicroRNA Assay kit (Applied Biosystems; Thermo Fisher Scientific, Inc.) was used, and qPCR was conducted as follows: $4 \mathrm{~min}$ at $94^{\circ} \mathrm{C}$, then 40 cycles of $94^{\circ} \mathrm{C}$ for $30 \mathrm{sec}, 60^{\circ} \mathrm{C}$ for $30 \mathrm{sec}$ and $72^{\circ} \mathrm{C}$ for $60 \mathrm{sec}$. U6 was used as an endogenous control. The primers used were as follows: Twist1, forward 5'-AGCTACGCCTTCTCCGTCT-3', reverse, 5'-TCCTTC
TCTGGAAACAATGACA-3'; $\beta$-actin, forward 5'-GGCGGC ACCACCATGTACCCT-3', reverse, 5'-AGGGGCCGGACT CGTCATACT-3'; U6, forward 5'-CTCGCTTCGGCAGC ACA-3', reverse, 5'-AACGCTTCACGAATTTGCGT-3'; and miR-186-5p, forward 5'-GCGGCGCAAAGAATTCTCCT-3' and reverse, 5'-GTGCAGGGTCCGAGGT-3'. The $2^{\Delta \Delta \mathrm{Cq}}$ method (16) was used to quantify the relative expression levels of Twist1 and miR-186-5p.

Cell transfection. miR-186-5p mimic (5'-CAAAGAAUU CUCCUUUUGGGCU-3', 5'-CCCAAAAGGAGAAUUCUU UGUU-3'), inhibitor (5'-AGCCCAAAAGGAGAAUUCUUU G-3'), mimic negative control (NC; 5'-UUCUCCGAACGU GUCACGUTT-3', 5'-ACGUGACACGUUCGGAGAATT-3') and inhibitor NC (5'-CAGUACUUUUGUGUAGUACAA-3') were synthesised by Guangzhou RiboBio Co., Ltd. The cell lines (U87, T98G) were seeded in 6-well plates at a density of $2 \times 10^{5}$ cells $/ \mathrm{ml}$, and then maintained for $24 \mathrm{~h}$ at $37^{\circ} \mathrm{C}$ in a $5 \% \mathrm{CO}_{2}$ humidified atmosphere. Cells were transfected with miR-186-5p mimics, miR-186-5p inhibitors, mimic NC or inhibitor NC using Lipofectamine ${ }^{\circledR} 2000$ (Invitrogen; Thermo Fisher Scientific, Inc.), at a final concentration of $100 \mathrm{nM}$ for 24 or $48 \mathrm{~h}$ at $37^{\circ} \mathrm{C}$. Twist1 small interfering RNA [siRNA (siTwist1-1: 5'-CCTCTGCATTCTGATAGAA-3'; siTwist1-2: 5'-TGAGCA ACAGCGAGGAAGA-3')] and siRNA NC (5'-UUCUCC GAACGUGUCACGUTT-3') were obtained from Guangzhou RiboBio Co., Ltd. siTwist1-2 (20 nM) induced notably increased effects on Twist1 expression compared with siTwist1-1 (20 nM), and was therefore selected for use as the si-Twist1 presented in this study (data not shown). The Twistl expression vector (pcDNA3.1-Twist1) was constructed by Shanghai GenePharma Co., Ltd. The pcDNA3.1-Twist1 vector $(2 \mu \mathrm{g} / \mathrm{ml})$ and empty vector control were transfected into cells using Lipofectamine 2000 , according to the manufacturer's protocols. At $24 \mathrm{~h}$ following transfection, RT-qPCR was performed. At $48 \mathrm{~h}$ following transfection, western blot, 5-ethynyl-2'-deoxyuridine $(\mathrm{EdU})$ and flow cytometry assays were performed.

Western blot analysis. Western blot analysis was performed as previously described (17). Cells or tissues were harvested in lysis buffer (10 mM Tris-HCl pH 7.5, $150 \mathrm{mM} \mathrm{NaCl,} 1 \%$ Triton $\mathrm{X}-100$ ) containing protease and phosphatase inhibitors (Roche Applied Science). The protein concentration was determined using a BCA kit (Pierce; Thermo Fisher Scientific, Inc.). Then, proteins $(20 \mu \mathrm{g} /$ lane $)$ were separated by $10 \%$ SDS-PAGE and transferred onto polyvinylidene difluoride membranes (EMD Millipore). Membranes were incubated for $1 \mathrm{~h}$ at room temperature in PBS- $0.1 \%$ Tween-20 and 5\% non-fat skim milk, and then probed at $37^{\circ} \mathrm{C}$ for $1 \mathrm{~h}$ with antibodies against Twist1 (1:500; cat. no. ab50581; Abcam) and $\beta$-actin (1:2,000; cat. no. ab8227; Abcam). After washing, the blots were incubated at $37^{\circ} \mathrm{C}$ for $1 \mathrm{~h}$ with horseradish peroxidase-conjugated secondary antibodies (1:30,000; cat. no. AP187P; EMD Millipore), and the signals were visualised using enhanced chemiluminescence substrate (Bio-Rad Laboratories, Inc.) by a luminescent image analyser (Fujifilm).

Luciferase reporter assays. To identify putative targets involved in the effects of miR-186 on the proliferation and drug resistance of glioblastoma cells, bioinformatics was employed using miRanda 
Table I. Comparison of clinicopathological features between the control and glioma groups.

\begin{tabular}{|c|c|c|c|}
\hline Clinicopathological features & Control group $(n=11)$ & Glioma group $(n=20)$ & P-value \\
\hline Sex & & & 0.76 \\
\hline Male & 6 & 11 & \\
\hline Female & 5 & 9 & \\
\hline Age (years) & $46(30-65)$ & $48(32-68)$ & 0.86 \\
\hline \multicolumn{4}{|l|}{ Tumour site } \\
\hline Frontal lobe & - & 4 & \\
\hline Temporal lobe & - & 4 & \\
\hline Parietal lobe & - & 2 & \\
\hline Occipital lobe & - & 3 & \\
\hline Insular lobe & - & 2 & \\
\hline Multiple lobes & - & 5 & \\
\hline \multicolumn{4}{|l|}{ Infiltration depth } \\
\hline $\mathrm{T} 1+\mathrm{T} 2$ & - & 4 & \\
\hline $\mathrm{T} 3+\mathrm{T} 4$ & - & 16 & \\
\hline Tumour diameter (cm) & - & $3.18 \pm 0.45$ & \\
\hline
\end{tabular}

version 3.3a (http://www.microrna.org/microrna/home.do). The wild-type (WT) 3'-UTR of Twist1 that contains the predicted miR-186-5p target sequence was amplified using Pyrobest DNA polymerase (Fermentas; Thermo Fisher Scientific, Inc.) and cloned into the miRNA Expression Reporter Vector (pGL3 vector; Promega Corporation) at the $\mathrm{XbaI}$ site. A mutation from GTA to CAT was introduced in the potential miR-186-5p binding sites (named pGL3-Twist1-Mut) by using the QuickChange Stratagene method. $293 \mathrm{~T}$ cells were seeded in a 24 -well plate $24 \mathrm{~h}$ prior to transfection at a density of $2.5 \times 10^{4}$ cells/well, and co-transfected with $0.15 \mu \mathrm{g}$ of pGL3-Twist1-WT or pGL3-Twist1-Mut, $0.05 \mu \mathrm{g}$ of the control vector containing Renilla luciferase (pRL-TK; Promega Corporation) and 40 pmol of miR-186-5p mimics or NC using Lipofectamine ${ }^{\circledR} 2000$. At 24 h following transfection, firefly and Renilla luciferase activity were measured using the Dual-Luciferase Reporter Assay system (Promega Corporation), and firefly luciferase activity was normalized to Renilla luciferase activity.

Evaluation of apoptosis. Post-transfection, cells were treated with TMZ $(100 \mu \mathrm{M})$ for $24 \mathrm{~h}$ at $37^{\circ} \mathrm{C}$. Cell death was detected using an Annexin V-phycoerythrin/7-aminoactinomycin D (7-AAD) apoptosis kit (BD Biosciences), according to the manufacturer's protocol. Cells were resuspended in $1 \mathrm{X}$ binding buffer (BD Biosciences) at a concentration of $1 \times 10^{6}$ cells $/ \mathrm{ml}$. Then, $5 \mu \mathrm{l}$ PE-Annexin V and $5 \mu 1$ 7-AAD were added. Cells were incubated for $15 \mathrm{~min}$ at room temperature in the dark. Then, $400 \mu l$ of $1 \mathrm{X}$ binding buffer was added to each tube, and samples were analysed using a flow cytometer (BD Biosciences). The data were analysed using FlowJo version 10 (FlowJo LLC).

5-ethynyl-2'-deoxyuridine (EdU) assay. Cells were seeded at a density of $2.5 \times 10^{4}$ cells/well in a 24 -well plate $24 \mathrm{~h}$ prior to transfection. Subsequently, cells were transfected with mimics, mimic NC, inhibitors and inhibitor NC as previously described. At $48 \mathrm{~h}$ following transfection, the cells were then fixed with $4 \%$ formaldehyde for $15 \mathrm{~min}$ at room temperature, and stained with an EdU DNA Proliferation In vitro Detection kit (Guangzhou RiboBio Co., Ltd.), according to the manufacturer's protocols. Images of three randomly selected fields were acquired to visualise the number of EdU-stained cells using a fluorescence microscope (Nikon Corporation), and the data were analysed using ImageJ version 1 (National Institutes of Health).

Analysis of cell proliferation and $I C_{50}$. A Cell Counting Kit-8 (CCK-8) Assay kit (Sigma-Aldrich; Merck KGaA) was used to measure cell proliferation and drug resistance. Cells were seeded in 96-well plates at a density of 5,000 cells/well and incubated for $24 \mathrm{~h}$. Then, the cells were treated with various concentrations $(0,5,10,20,40,80,160$ and $320 \mu \mathrm{M})$ of TMZ and incubated for 24,48 and $72 \mathrm{~h}$ in $37^{\circ} \mathrm{C}$. CCK-8 solution $(10 \mu \mathrm{l})$ was added to each well and cells were incubated for $2 \mathrm{~h}$ at $37^{\circ} \mathrm{C}$. The absorbance was detected at $450 \mathrm{~nm}$ using a Multi-mode Plate Reader (BioTek Instruments, Inc.). $\mathrm{IC}_{50}$ values were calculated from dose-response curves generated using a polynomial dose-response approximation using SPSS version 17.0 software (SPSS, Inc.).

Statistical analysis. Statistical analysis was performed using SPSS version 13.0 software (SPSS, Inc.). All results are expressed as the means \pm standard deviation of three independent experiments. Comparison of means between two groups was performed using Student's t-test. Comparisons of means between multiple groups were conducted using one-way analyses of variance followed by post hoc pairwise comparisons using Tukey's test. Differences in miRNA expression levels between normal and GBM brain tissues were evaluated using Mann-Whitney $\mathrm{U}$ tests. $\mathrm{P}<0.05$ was considered to indicate a statistically significant difference.

\section{Results}

miR-186-5p is downregulated in glioblastoma and contributes to the proliferation of glioblastoma cells. To determine whether 
A

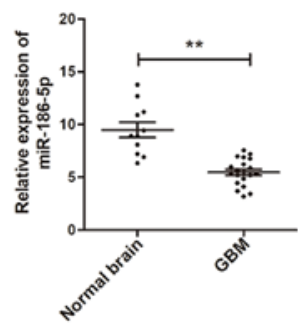

D

$E$
B

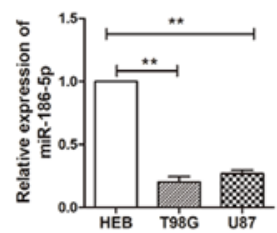

C

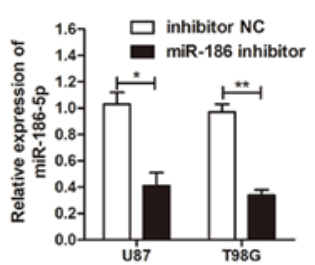

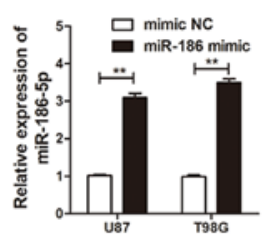

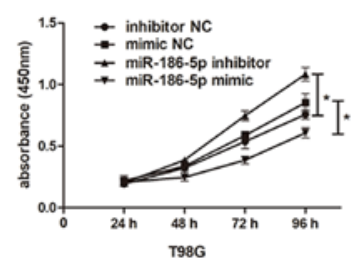

G

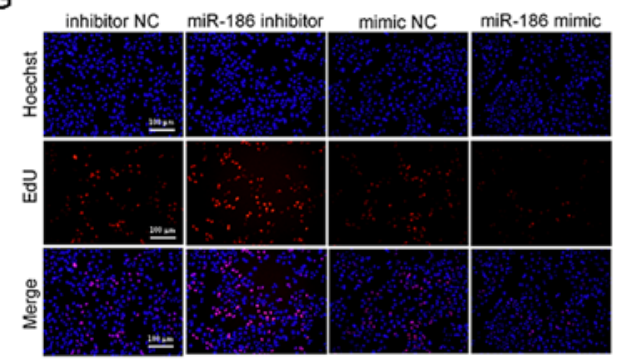

$\mathrm{H}$

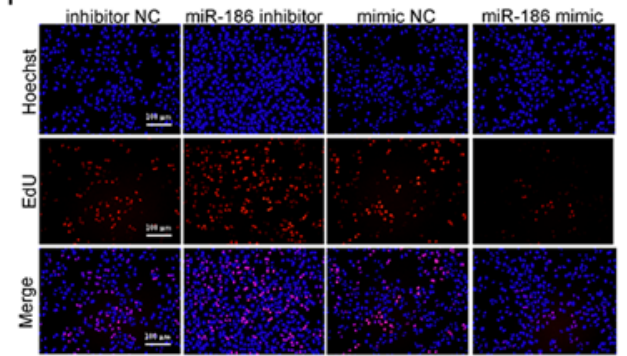

$\mathrm{F}$

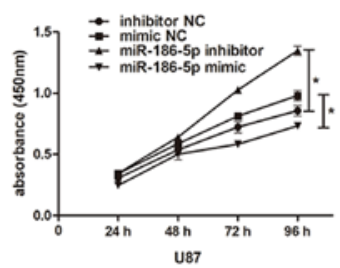

U87
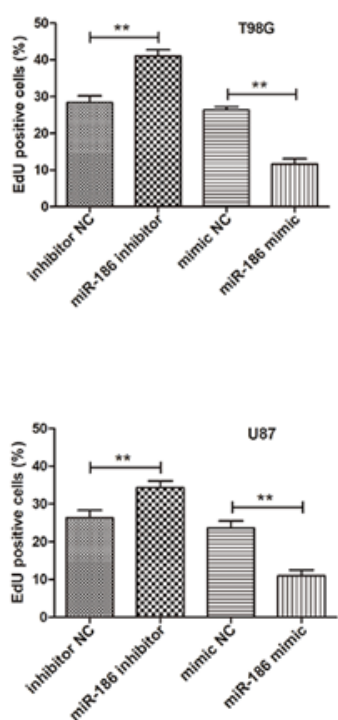

Figure 1. miR-186-5p is downregulated in glioblastoma. (A) Expression of miR-186-5p in GBM and normal non-neoplastic tissues, as determined by RT-qPCR analysis. (B) Expression of miR-186-5p in HEB, T98G and U87 cells, as determined by RT-qPCR analysis. miR-186-5p expression in T98G and U87 cells transfected with (C) miR-186-5p inhibitors or inhibitor NC, and (D) miR-186-5p mimics or mimic NC. Proliferation of (E) T98G and (F) U87 cells transfected with miR-186-5p inhibitors, mimics or their NC, as determined via a Cell Counting kit-8 assay. Proliferation of (G) T98G and (H) U87 cells transfected with miR-186-5p inhibitors, mimics or their NC, as determined by an EdU assay (scale bar=100 $\mu$ m). All data are presented as the means \pm standard deviation. ${ }^{*} \mathrm{P}<0.05,{ }^{* *} \mathrm{P}<0.01$. EdU, 5-ethynyl-2'-deoxyuridine; GBM, glioblastoma multiforme; miR-186-5p, microRNA-186-5p; NC, negative control; RT-qPCR, reverse transcription-quantitative PCR.

miR-186-5p is involved in human glioblastoma, the expression levels of miR-186-5p were detected in human glioblastoma tissues and two human glioblastoma cell lines [U87 (likely glioblastoma of unknown origin) and T98G] via RT-qPCR analysis. The results revealed that miR-186-5p levels in human glioblastoma tissues were significantly reduced compared with in normal brain tissues (Fig. 1A). It was also demonstrated that miR-186-5p was significantly downregulated in U87 and T98G cells compared with in the human normal glial cell line, HEB (Fig. 1B). To investigate the effects of miR-186-5p on the proliferation of glioblastoma cells, proliferation was measured using CCK- 8 and EdU assays $24 \mathrm{~h}$ post-transfection of U87 and T98G cells with miR-186-5p mimics, mimic NC, miR-186-5p inhibitors and inhibitor NC. It was revealed that upregulated miR-186-5p expression significantly decreased the proliferation of U87 and T98G cells compared with the $\mathrm{NC}$, whereas inhibition of miR-186-5p significantly increased the proliferation of U87 and T98G cells (Fig. 1C-H). These results indicated that miR-186-5p was downregulated in GBM tissues and cells and suppressed the proliferation of glioblastoma cells.

miR-186-5p decreases TMZ resistance in glioblastoma cells. TMZ has been widely used as a treatment for glioblastoma. U87 and T98G cells were treated with TMZ (50, 100 and $200 \mu \mathrm{M}$ ) for $24 \mathrm{~h}$; it was demonstrated that miR-186-5p was significantly downregulated in U87 and T98G cells treated with TMZ (Fig. 2A and B). Subsequently, the $\mathrm{IC}_{50}$ values of TMZ in U87 and T98G cells transfected with miR-186-5p mimics or $\mathrm{NC}$ were investigated, and the results revealed that 
A

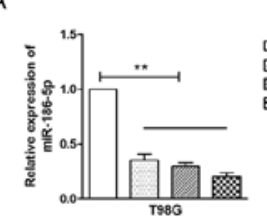

E

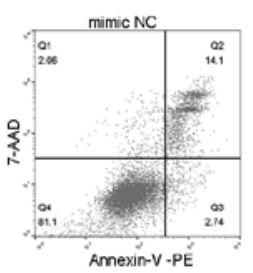

$\mathrm{F}$

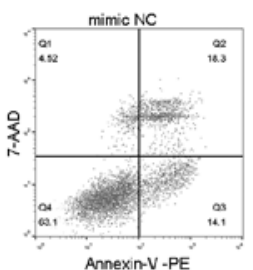

B

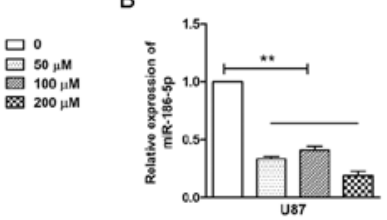

C

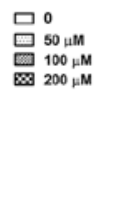

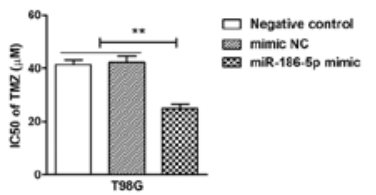

D

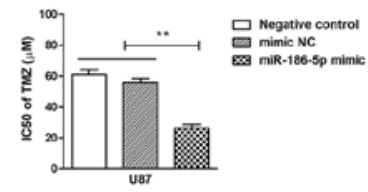

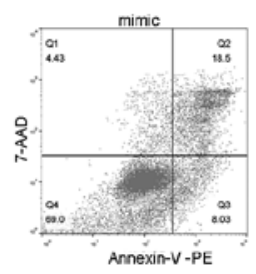
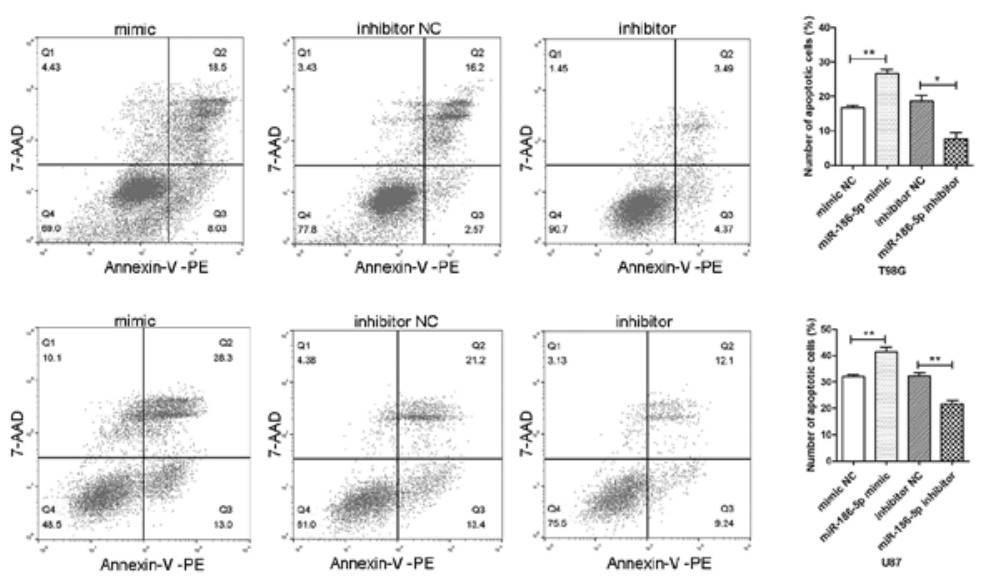

Figure 2. miR-186-5p reduces the TMZ resistance of glioblastoma cells. Reverse transcription-quantitative PCR analysis of the relative expression levels of miR-186-5p in (A) T98G and (B) U87 cells treated with TMZ (0, 50, 100 and $200 \mu \mathrm{M})$ for $24 \mathrm{~h}$. IC 50 values of TMZ in (C) T98G and (D) U87 cells transfected with miR-186-5p mimics, mimic NC or blank control, as determined via a Cell Counting Kit-8 assay. Flow cytometric analysis of the apoptosis of (E) T98G and (F) U87 cells transfected with miR-186-5p inhibitors, mimics or their NC and treated with $100 \mu \mathrm{M}$ TMZ for $24 \mathrm{~h}$. All data are presented as the means \pm standard deviation. "P<0.05, ${ }^{* *} \mathrm{P}<0.01$. 7-AAD, 7-aminoactinomycin; PE, phycoerythrin; miR-186-5p, microRNA-186-5p; NC, negative control; TMZ, temozolomide.

A

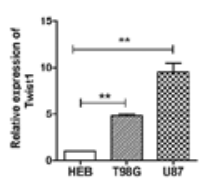

C
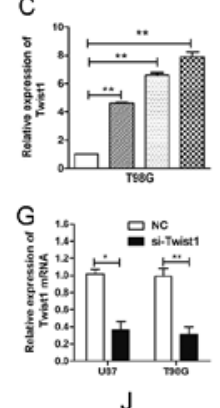

J

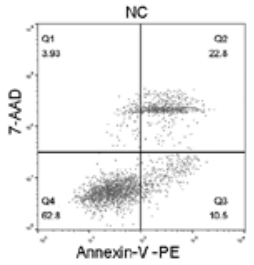

B

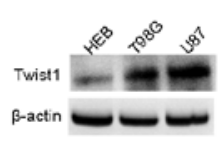

D

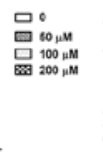

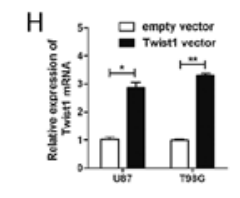

E

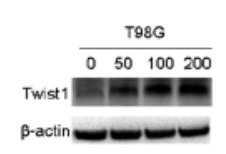

F
1
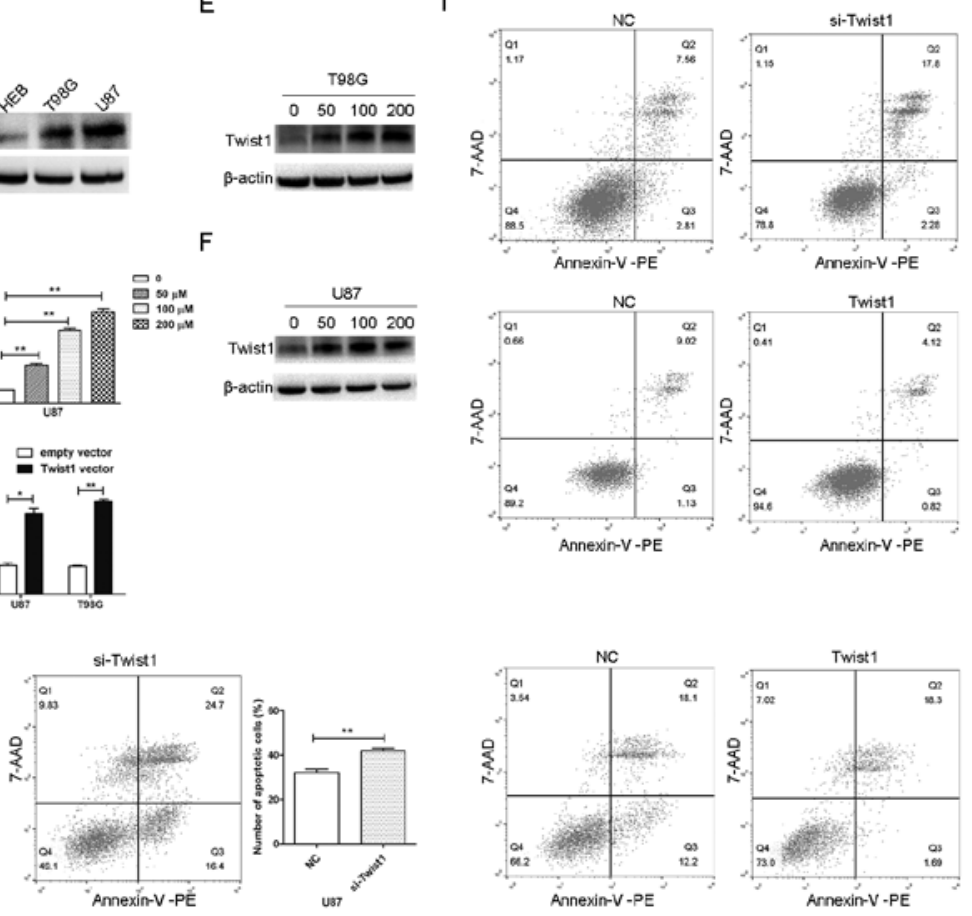

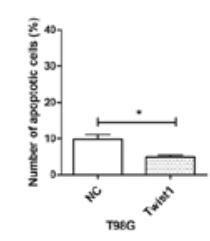

Figure 3. Twist1 is associated with the TMZ resistance of glioblastoma cells. (A) Twist1 mRNA and (B) protein levels in HEB, T98G and U87 cells, as determined by RT-qPCR and western blot analysis, respectively. (C and D) Twist1 mRNA and (E and F) protein levels in (C and E) T98G and (D and F) U87 cells treated with TMZ $(0,50,100$, and $200 \mu \mathrm{M})$ for $24 \mathrm{~h}$, as determined by RT-qPCR and western blot analysis, respectively. Expression of Twist1 mRNA in U87 and T98G cells transfected with (G) si-Twist1 or siRNA NC, and (H) Twist1 vector or empty vector. Flow cytometric analysis of the apoptosis of (I) T98G and (J) U87 cells transfected with si-Twist1, Twistl vector or NC, and treated with $100 \mu \mathrm{M}$ TMZ for $24 \mathrm{~h}$. All data are presented as the means \pm standard deviation. "P<0.05, ${ }^{* *} \mathrm{P}<0.01$. 7-AAD, 7-aminoactinomycin; PE, phycoerythrin; miR-186-5p, microRNA-186-5p; NC, negative control; RT-qPCR, reverse transcription-quantitative PCR; si/siRNA, small interfering RNA; TMZ, temozolomide; Twist1, Twist-related protein 1.

miR-186-5p significantly decreased the $\mathrm{IC}_{50}$ values of TMZ in glioblastoma cells (Fig. 2C and D). Furthermore, the apoptosis of U87 and T98G cells was measured following treatment with $100 \mu \mathrm{M}$ TMZ via flow cytometry, and it was observed that 
A

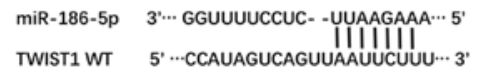

C

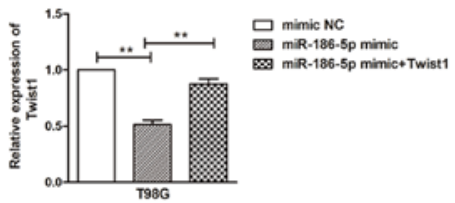

E

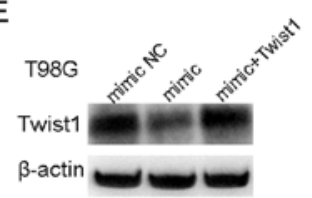

G

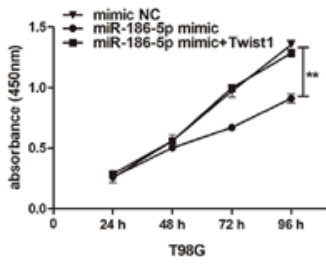

I

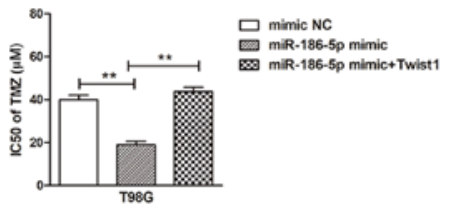

B
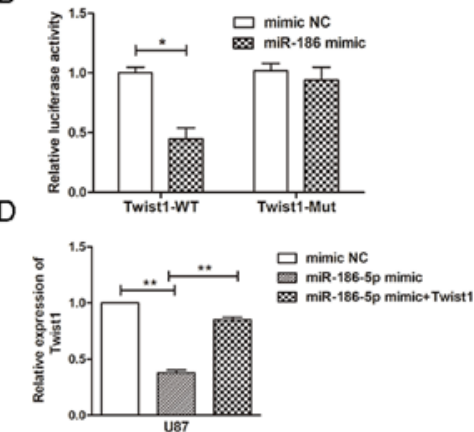

F

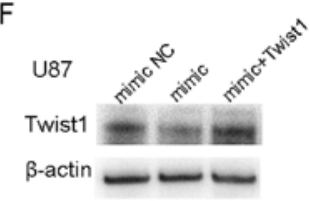

$\mathrm{H}$

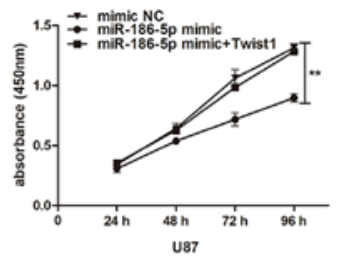

J

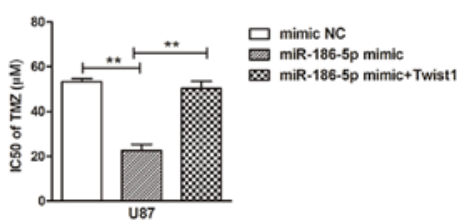

Figure 4. miR-186-5p contributes to the proliferation and drug resistance of glioblastoma cells by targeting Twist1. (A) Potential binding sites of miR-186-5p in the 3'UTR of Twist1. (B) 293T cells were co-transfected with miR-186-5p and reporter plasmids containing the WT or MUT 3'UTR of Twist1. Expression of Twist1 mRNA in (C) T98G and (D) U87 cells transfected with miR-186-5p mimic with or without Twist1 vector, as determined via reverse transcription-quantitative PCR. Expression of Twist1 protein in (E) T98G and (F) U87 cells transfected with miR-186-5p mimic with or without Twist1 vector, as determined by western blot analysis. Proliferation of (G) T98G and (H) U87 cells transfected with miR-186-5p mimic with or without Twist1 vector, as determined via a CCK-8 assay. $\mathrm{IC}_{50}$ values of TMZ in (I) T98G and (J) U87 cells transfected with miR-186-5p mimic with or without Twist1 vector as determined via a CCK-8 assay. All data are presented as the means \pm standard deviation. ${ }^{*} \mathrm{P}<0.05,{ }^{* *} \mathrm{P}<0.01$. CCK-8, Cell Counting kit-8; miR-186-5p, microRNA-186-5p; MUT, mutant; NC, negative control; Twist1, Twist-related protein 1; 3'-UTR, 3'-untranslated region; WT, wild-type.

miR-186-5p overexpression significantly increased the number of apoptotic cells, whereas miR-186-5p inhibition reduced the number of apoptotic cells (Fig. 2E and F). The results suggested that downregulation of miR-186-5p contributed to the development of TMZ resistance in glioblastoma cells.

Twistl is associated with the drug resistance of glioblastoma cells. It has been reported that Twist1 is upregulated in glioblastoma and promotes the invasion of glioblastoma cells (15). In the present study, it was observed that the expression levels of Twist1 were significantly higher in U87 and T98G cell lines compared with in HEB cells (Fig. 3A and B). In addition, it was demonstrated that Twist mRNA and protein levels were increased in U87 and T98G cells treated with TMZ compared with the control (Fig. 3C-F). To investigate whether Twist1 was involved in the drug resistance of glioblastoma cells, U87 and T98G cells were transfected with si-Twist1 or Twist1 overexpression vector. Si-Twist1 significantly downregulated the expression of Twist1 in U87 and T98G cells, whereas Twist1 vector upregulated the expression of Twist1 (Fig. 3G and H).
Subsequently, transfected T98G and U87 cells were treated with $100 \mu \mathrm{M} \mathrm{TMZ}$; it was observed that the overexpression of Twist1 decreased TMZ-induced apoptosis, whereas the inhibition of Twist1 increased the number of apoptotic T98G and U87 cells (Fig. 3I and J). Twist1 overexpression and knockdown most notably affected the number of early apoptotic U87 cells (Fig. 3I and J). These data suggested that Twist1 was involved in the drug resistance of glioblastoma cells, and that Twist 1 may primarily affect the early apoptosis of U87 cells. In addition, it was observed that when cells were treated with $100 \mu \mathrm{M} \mathrm{TMZ}\left(>\mathrm{IC}_{50}\right.$; Fig. 2B), the percentage of apoptotic cells was $<50 \%$ (Fig. 3J); it may be that the percentage of dead cells was $>50 \%$ cells, but that these dead cells presented as cell debris that were not detected as apoptotic cells.

miR-186-5p contributes to the proliferation and drug resistance of glioblastoma cells by targeting Twist1. It was predicted that Twist1 was a potential target of miR-186-5p. The binding sites of miR-186-5p and Twist1 are presented in (Fig. 4A). To verify that Twist1 was a direct target of 
miR-186-5p, luciferase reporter assays were conducted, and it was revealed that miR-186-5p significantly inhibited the luciferase activity of reporters containing the WT, but not the MUT 3'UTR of Twistl (Fig. 4B). To determine whether miR-186-5p regulates the expression of Twist1, glioblastoma cells were transfected with miR-186-5p mimics with or without Twist1 vector. The results demonstrated that miR-186-5p transfection significantly suppressed the expression of Twist $1 \mathrm{mRNA}$ and protein, whereas overexpression of Twistl significantly reversed the effects of miR-186-5p mimic (Fig. 4C-F). To investigate whether miR-186-5p affected the proliferation and drug resistance of glioblastoma cells by targeting Twist1, the $\mathrm{IC}_{50}$ of $\mathrm{TMZ}$ in, and proliferation of U87 and T98G cells following transfection with miR-186-5p mimics with or without Twist vector was determined. Overexpression of miR-186-5p significantly decreased cell proliferation and the $\mathrm{IC}_{50}$ of TMZ, whereas the overexpression of Twist1 reversed the effects of miR-186-5p on cell proliferation and the $\mathrm{IC}_{50}$ of TMZ in glioblastoma cells (Fig. 4G-J). The results indicated that Twist1 may be a functional target of miR-186-5p.

\section{Discussion}

In the present study, it was demonstrated that miR-186-5p was downregulated in glioblastoma cell lines and tissues. Silencing of miR-186-5p increased the proliferation and decreased the apoptosis of glioblastoma cells, whereas ectopic overexpression of miR-186-5p induced opposing effects. Recently, Jiang et al (18) also reported that miR-186 is downregulated in glioblastoma tissue, and that upregulation of miR-186 decreases cell proliferation. In addition, it was demonstrated that miR-186-5p may be involved in the TMZ resistance of glioblastoma cells. The present findings indicated that miR-186-5p served a role in the proliferation and TMZ resistance of glioma cells via the direct targeting of Twist1. Conversely, Jiang et al (18) reported insulin-like growth factor 1 receptor to be a target of miR-186; therefore, Twist1 may not be the only functionally relevant target of miR-186-5p in glioblastoma.

miR-186 has previously been investigated in various tumours. In NSCLC, miR-186 expression is downregulated compared with in normal lung tissues or epithelial cell lines, and it is associated with patient survival (11). Further studies have indicated that overexpression of miR-186 in NSCLC cells inhibits proliferation by inducing $G_{1} / S$ checkpoint arrest (11). Conversely, it has been reported that miR-186 is a tumour-promoting miRNA in endometrial cancer and hepatic carcinoma by targeting the tumour suppressors forkhead box protein $\mathrm{O} 1$ and A-kinase anchoring protein 12, respectively $(19,20)$. The present study suggested that miR-186-5p acts as a tumour suppressor in glioblastoma, and that Twist1 was the functional target of miR-186-5p.

Drug resistance is the main reason for the failure of chemotherapeutic treatment of glioma. Numerous studies have reported that certain miRNAs, including miR-634, miR-205 and miR-497, contribute to drug resistance in glioma $(17,21,22)$. For example, miR-497 is upregulated in glioma and hypoxia induces the expression of miR-497. Ectopic overexpression of miR-497 decreases the sensitivity of glioma cells to TMZ by targeting programmed cell death protein 4 (17). To the best of our knowledge, the present study was the first to report that downregulation of miR-186-5p in GBM promoted the proliferation and drug resistance of glioma cells.

It has been demonstrated that miR-186 serves a role in cell biological processes by inhibiting the expression of its downstream targets, including $\beta$-secretase 1 , collagen type $\mathrm{V} \alpha 1$, casein kinase $2 \alpha$ and Twist1 (9,23-25). In the present study, Twist 1 was identified as a direct downstream target of miR-186-5p. It was demonstrated that miR-186-5p overexpression downregulated the expression of Twist1 in glioma cells. Ectopic expression of miR-186-5p in glioma cells reduced cell proliferation, and the $\mathrm{IC}_{50}$ of $\mathrm{TMZ}$ and the levels of Twist1 in U87 and T98G cells. Conversely, overexpression of Twist1 rescued the miR-186-5p-induced decrease in cell proliferation and the $\mathrm{IC}_{50}$ of TMZ. These data suggested that miR-186-5p participated in the proliferation and drug resistance of glioblastoma cells by targeting Twist1. The results further indicated that Twist1 may primarily affect the early apoptosis of U87 cells; however, it was observed that miR-186-5p inhibition or overexpression notably affected the number of early and late apoptotic U87 cells. This may be due to miR-186-5p influencing the apoptosis of U87 cells by regulating the expression of other genes aside from Twist1.

It has been reported that Twist1, a basic-helix-loop-helix transcription factor, serves a role in the regulation of EMT, cell proliferation, cell migration, stem cell self-renewal, tumour initiation, senescence and drug resistance $(12,26,27)$. Twist1 is overexpressed in various types of tumour, including glioma, skin tumours, breast and ovarian cancer, and melanoma $(15,28,29)$. Mechanistically, Twist1 has been revealed to prevent apoptosis or senescence by inhibiting key regulators of the p16 and/or p53 pathways $(14,26)$; however, in the study, the mechanisms by which Twist1 regulated apoptosis and proliferation were not investigated.

In conclusion, the findings of the present study revealed that miR-186-5p was downregulated in glioblastoma cells and tissues, and functioned as a tumour suppressor. Biological or pharmacological intervention based on miR-186-5p may have therapeutic potential in reversing drug resistance and improving chemotherapeutic efficacy in human glioblastoma.

\section{Acknowledgements}

Not applicable.

\section{Funding}

The present study was supported by the Natural Science Foundation of Jiangxi Province (grant no. 20161BAB215230) and the Science and Technology Research Project of Jiangxi Province Education Department (grant no. GJJ150119).

\section{Availability of data and materials}

The datasets used and/or analyzed during the current study are available from the corresponding author on reasonable request.

\section{Authors' contributions}

$\mathrm{CW}$ conceived and designed the experiments; YX and $\mathrm{RC}$ performed the experiments; LW and SW analyzed and 
interpreted the data, YT and LZ contributed to the analysis of data and drafted the manuscript. All authors gave final approval of the version to be published.

\section{Ethics approval and consent to participate}

This study was approved by the Ethics Committee of The First Affiliated Hospital of Nanchang University and protocols were conducted according to the principles of the Declaration of Helsinki. Written informed consent was obtained from all patients in the study.

\section{Patient consent for publication}

Not applicable.

\section{Competing interests}

The authors declare that they have no competing interests.

\section{References}

1. Lathia JD, Mack SC, Mulkearns-Hubert EE, Valentim CL and Rich JN: Cancer stem cells in glioblastoma. Genes Dev 29: 1203-1217, 2015

2. Kim SS, Harford JB, Pirollo KF and Chang EH: Effective treatment of glioblastoma requires crossing the blood-brain barrier and targeting tumors including cancer stem cells: The promise of nanomedicine. Biochem Biophys Res Commun 468: 485-489, 2015.

3. Mirimanoff RO: High-grade gliomas: Reality and hopes. Chin J Cancer 33: 1-3, 2014.

4. Grauer OM, Wesseling P and Adema GJ: Immunotherapy of diffuse gliomas: Biological background, current status and future developments. Brain Pathol 19: 674-693, 2009.

5. Patil SA, Hosni-Ahmed A, Jones TS, Patil R, Pfeffer LM and Miller DD: Novel approaches to glioma drug design and drug screening. Expert Opin Drug Discov 8: 1135-1151, 2013.

6. Bartel DP: MicroRNAs: Target recognition and regulatory functions. Cell 136: 215-233, 2009.

7. Lujambio A and Lowe SW: The microcosmos of cancer. Nature 482: 347-355, 2012.

8. Sarkar FH, Li Y, Wang Z, Kong D and Ali S: Implication of microRNAs in drug resistance for designing novel cancer therapy. Drug Resist Updat 13: 57-66, 2010.

9. Zhu X, Shen H, Yin X, Long L, Xie C, Liu Y, Hui L, Lin X, Fang Y, Cao Y, et al: miR-186 regulation of Twist1 and ovarian cancer sensitivity to cisplatin. Oncogene 35: 323-332, 2016.

10. Erdmann K, Kaulke K, Thomae C, Huebner D, Sergon M, Froehner M, Wirth MP and Fuessel S: Elevated expression of prostate cancer-associated genes is linked to down-regulation of microRNAs. BMC Cancer 14: 82, 2014.

11. Cai J, Wu J, Zhang H, Fang L, Huang Y, Yang Y, Zhu X, Li R and Li M: miR-186 downregulation correlates with poor survival in lung adenocarcinoma, where it interferes with cell-cycle regulation. Cancer Res 73: 756-766, 2013.

12. Yang J, Mani SA, Donaher JL, Ramaswamy S, Itzykson RA, Come C, Savagner P, Gitelman I, Richardson A and Weinberg RA: Twist, a master regulator of morphogenesis, plays an essential role in tumor metastasis. Cell 117: 927-939, 2004.
13. Wang X, Ling MT, Guan XY, Tsao SW, Cheung HW, Lee DT and Wong YC: Identification of a novel function of TWIST, a bHLH protein, in the development of acquired taxol resistance in human cancer cells. Oncogene 23: 474-482, 2004.

14. Maestro R, Dei Tos AP, Hamamori Y, Krasnokutsky S, Sartorelli V, Kedes L, Doglioni C, Beach DH and Hannon GJ: Twist is a potential oncogene that inhibits apoptosis. Genes Dev 13: 2207-2217, 1999.

15. Mikheeva SA, Mikheev AM, Petit A, Beyer R, Oxford RG, Khorasani L, Maxwell JP, Glack in CA, Wakimoto H, González-Herrero I, et al: TWIST1 promotes invasion through mesenchymal change in human glioblastoma. Mol Cancer 9: 194, 2010.

16. Livak KJ and Schmittgen TD: Analysis of relative gene expression data using real-time quantitative PCR and the 2(-Delta Delta C(T)) method. Methods 25: 402-408, 2001.

17. Lan J, Xue Y, Chen H, Zhao S, Wu Z, Fang J, Han C and Lou M: Hypoxia-induced miR-497 decreases glioma cell sensitivity to TMZ by inhibiting apoptosis. FEBS Lett 588: 3333-3339, 2014.

18. Jiang J, Wang W, Fang D, Jin X, Ding L and Sun X: MicroRNA186 targets IGF-1R and exerts tumor-suppressing functions in glioma. Mol Med Rep 16: 7821-7828, 2017.

19. Myatt SS, Wang J, Monteiro LJ, Christian M, Ho KK, Fusi L, Dina RE, Brosens JJ, Ghaem-Maghami S and Lam EW: Definition of microRNAs that repress expression of the tumor suppressor gene FOXO1 in endometrial cancer. Cancer Res 70: 367-377, 2010.

20. Goeppert B, Schmezer P, Dutruel C, Oakes C, Renner M, Breinig M, Warth A, Vogel MN, Mittelbronn M, Mehrabi A, et al: Down-regulation of tumor suppressor A kinase anchor protein 12 in human hepatocarcinogenesis by epigenetic mechanisms. Hepatology 52: 2023-2033, 2010.

21. Tan Z, Zhao J and Jiang Y: MiR-634 sensitizes glioma cells to temozolomide by targeting CYR61 through Raf-ERK signaling pathway. Cancer Med 7: 913-921, 2018.

22. Li FF, Xing C, Wu LL and Xue F: MiR-205 enhances cisplatin sensitivity of glioma cells by targeting E2F1. Eur Rev Med Pharmacol Sci 22: 299-306, 2018.

23. Kim J, Yoon H, Chung DE, Brown JL, Belmonte KC and Kim J: miR-186 is decreased in aged brain and suppresses BACE1 expression. J Neurochem 137: 436-445, 2016.

24. Lei GS, Kline HL, Lee CH, Wilkes DS and Zhang C: Regulation of Collagen V expression and epithelial-mesenchymal transition by miR-185 and miR-186 during idiopathic pulmonary fibrosis. Am J Pathol 186: 2310-2316, 2016.

25. Lee YH, Kim SY and Bae YS: Upregulation of miR-760 and miR-186 is associated with replicative senescence in human lung fibroblast cells. Mol Cells 37: 620-627, 2014.

26. Lee KE and Bar-Sagi D: Oncogenic KRas suppresses inflammation-associated senescence of pancreatic ductal cells. Cancer Cell 18: 448-458, 2010.

27. Beck B, Lapouge G, Rorive S, Drogat B, Desaedelaere K, Delafaille S, Dubois C, Salmon I, Willekens K, Marine JC and Blanpain C: Different levels of Twist1 regulate skin tumor initiation, stemness, and progression. Cell Stem Cell 16: 67-79, 2015.

28. Ansieau S, Morel AP, Hinkal G, Bastid J and Puisieux A: TWISTing an embryonic transcription factor into an oncoprotein. Oncogene 29: 3173-3184, 2010

29. Nordfors K, Haapasalo J, Makela K, Granberg KJ, Nykter M, Korja M, Paavonen T, Haapasalo H and Soini Y: Twist predicts poor outcome of patients with astrocytic glioma. J Clin Pathol 68: 905-912, 2015. 